\title{
Agricultural valorization by biotransformation of fish wastes combined with grape marc and molasses
}

\author{
Dounia Lakhal ${ }^{1}$, Bouchaib Bahlaouan ${ }^{1,2}$, Nadia Boutaleb ${ }^{1, *}$, Mohamed Bennani ${ }^{3}$ and Said El Antri ${ }^{1}$ \\ ${ }^{1}$ Hassan II University of Casablanca, Laboratory of Biochemistry, Environment, and Agri-Food, URAC36, \\ 20650 Morocco \\ ${ }^{2}$ Higher Institutes of the Nursing Professions and Techniques of Health (ISPITS), Casablanca 22500, Morocco \\ ${ }^{3}$ Pasteur Institute of Morocco, Laboratory of Physico-Chemical Analysis of Water, Food and Environment, \\ Casablanca
}

\begin{abstract}
Since the advent of agriculture, organic wastes have been used to fertilize agricultural soils. The sustainability of the recovery of these wastes depends on the quality of the products developed in order to meet the expectations of the agricultural profession. The objective of our study was to evaluate the quality of the biotransformation of a ternary mixture of industrial waste: fish waste, molasses, and grape marc. Several balanced mixtures were developed and underwent natural biotransformation for two weeks to produce a fertilizer of good nutritional and microbiological quality. Quality control parameters $(\mathrm{pH}$, conductivity, dry matter, phosphorus, nitrogen, potassium, carbon, etc.) were monitored during the time stipulated for biotransformation.
\end{abstract}

The results showed that the bio-fertilizer generated from the mentioned wastes is characterized by good agronomic quality (rich in phosphorus, nitrogen, and potassium), mature, with a stable $\mathrm{pH}$ and had an excellent hygienic condition, due to the absence of spoilage microorganisms, which would constitute a major obstacle to the adoption of this practice.

The fertilization test showed that our product is more interesting than commercial fertilizer. Triangular surfaces of iso-responses are established to identify the relevant formulations leading to a product of specific interest to build in practice a predictive operational model for industrial waste management. The biotransformation of a mixture consisting of approximately $50 \%$ of fish waste, $12.5 \%$ molasses, and $37.50 \%$ grape marc is an optimal formulation to generate a product rich in the nutrients essential for optimal growth plants (nitrogen, phosphorus, and potassium). The formulas do not integrate the grape marc was the most unfavorable mixtures from their efficacy and/or health safety criteria.

Keywords: Organic waste; biotransformation; mixture designs; triangular surfaces of iso-responses; grape marc; bio-fertilizer.

\section{Introduction}

The food processing industry in Morocco is a strategic sector. It is the leading manufacturing sector in Morocco. The development of these industrial activities has generated a large quantity of solid waste, which comes in particular from the processing of organic raw materials. This is a real nuisance to the environment (pollution of air, soil, and water). The grape marc is the main by-product derived from winemaking ${ }^{1}$, composed of skins, seeds, and grape stalks ${ }^{2}$. This by-product has a high nutritional value; it contains about $20 \%$ of the weight of the grapes used for winemaking ${ }^{3}$, which is no longer used. Its recovery by a return to the earth is part of the logic of recycling organic matter. Their chemical composition is variable depending on the type of marc and the

*Corresponding author: Nadia Boutaleb

Email address: nadia.boutaleb@univh2c.ma

DOI: http://dx.doi.org/10.13171/mjc10702008071447nb parties involved 4,5 . Due to their abundance, availability, and nutritive content, this waste draws attention to the production of high-value mixtures that can be used as bio-fertilizers ${ }^{6}$. To limit the pollution generated by grape marc, the use of a new biotechnological waste management process is receiving considerable interest worldwide. In addition to that, wastes which are resulting from the processing fish (composed of heads, viscera, bones, tails, fins, and skins) is characterized as a source of the significant source of emission of unpleasant odors, air pollution, and pollution of groundwater ${ }^{7}$ by relatively rapid biological decomposition and considered.

The main objective of this work was the recovery of these organic pollutants (grape marc and fish waste) by biotransformation. This necessitated mixing it with 
other wastes and by-products of agro-food industries such as sugar molasses to balance the elemental composition of the starting mixture (carbon, nitrogen, phosphorus). It is therefore essential to use an experimental design according to a centroid simplex in order to be able to optimize the acquisition of the information and to estimate the effect of each factor studied and to distinguish which optimal configuration will be needed to ensure this biotransformation towards the generation of an interested nutritionally product. This wok exposes an evolution of physicochemical and nutritional parameters of the testes compositions, microbiological tests testifying the salubrity of the finished products and a study of toxicity and germination on the barley crop.

\section{Material and Methods}

\subsection{Preparation of Mixture}

For the present study, seven formulas were prepared (using variable proportions) based on three components: The grape marc was recovered from a wine industry. About $5 \mathrm{~kg}$ of grape marc obtained after pressing the grapes and then transported to the laboratory. On arrival, the stalks were manually removed from the raw material, which was then dried at $45^{\circ} \mathrm{C}$ for 24 hours and dry crushed, then the grape marc was mixed with the industrial waste of sardines, molasses sugar. The yeast Saccharomyces cerivisiae is used as a biotransformation agent and is added at a fixed mass ratio of $1 \%$.

The set is put in plastic boxes ( $\mathrm{L} \mathrm{x} \mathrm{W} \mathrm{x} \mathrm{H}(\mathrm{cm})$ : $16.5 \mathrm{x}$ $10.5 \times 8)$ of the capacity of one liter. To ensure aeration, stirring of the contents is carried out using a benchtop stirrer $(100 \mathrm{rpm})$. For economic and technical reasons, the tests were organized according to a plan of mixtures with constraints; Preliminary work from our laboratory indicated that ${ }^{8}$ :

- The use of waste of fish alone leads to liquefaction of the biotransformation substrate. This comes down to the fact that this waste has a low $\mathrm{C} / \mathrm{N}(<6)$ ratio and then undergoes unfavorable biotransformation.

- Fish waste is the most abundant, very rich in phosphorus, the lower constraint relating to its introduction into the biotransformation mixture is $50 \%$.

- Add of molasses helps to improve the $\mathrm{C} / \mathrm{N}$ ratio, and can be used to balance a fish waste substrate, the upper constraint relating to its introduction into the biotransformation mixture is $12.5 \%$.

The biotransformation substrate is based on fish waste, which has a meager $\mathrm{C} / \mathrm{N}$ ratio $(<6)$. This ingredient ensures a contribution, especially in nitrogen and also in phosphorus. This justifies the low value of the $\mathrm{C} / \mathrm{N}$ ratio.

According to the literature ${ }^{8}$, to having favorable biotransformation and ensure the convention of organic matter to a stabilized product rich in nutrients assimilable by plants, it will be necessary to correct this ratio so that it is between 15 and 30 . It then seems essential to balance the mixture with other ingredients (also waste or industrial by-products), ensuring a source of carbon. Based on the nutritional characterization of the substrates carried out in our laboratory, sugar molasses can constitute a source of carbon $(\mathrm{C} / \mathrm{N}$ very high around $57 \%)$. On the other hand, it is deficient in phosphorus. The grape marc, like molasses, an industrial by-product, presents a $\mathrm{C} / \mathrm{N}$ ratio of around $30 \%$ and relatively more abundant in phosphorus. In the study of the formulations, the simplex mixing plans seem to be well suited to solve the studies on the formulations, the experimental centroid simplex plan with 7-points experimental was therefore chosen (Table 1).

The different compositions prepared are controlled for 2 weeks of biotransformation by the quality control parameters. The studied mixtures are presented in Table 1.

Table 1. Mix plan test matrix consisting of a 7-point experimental centroid simplex plane (the tests).

\begin{tabular}{|c|c|c|c|}
\hline Mixture $\mathbf{N}^{\circ}$ (name) & Fish waste (\%) & Molasses (\%) & Grape marc (\%) \\
\hline $\mathbf{1}$ (M1) & 50.00 & 50.00 & 0.00 \\
\hline $\mathbf{2}$ (M2) & 62.50 & 25.00 & 12.50 \\
\hline $\mathbf{3}$ (M3) & 87.50 & 12.50 & 0.00 \\
\hline $\mathbf{4}$ (M4) & 50.00 & 12.50 & 37.50 \\
\hline $\mathbf{5}$ (M5) & 68.75 & 12.50 & 18.75 \\
\hline $\mathbf{6}$ (M6) & 68.75 & 31.25 & 0.00 \\
\hline $\mathbf{7}$ (M7) & 50.00 & 31.25 & 18.75 \\
\hline
\end{tabular}

\subsection{Chemical and physicochemical analysis} The $\mathrm{pH}$, conductivity, dry matter (DM), and temperature are measured daily according to the method described by Taha et al. (2004) ${ }^{8}$.

\subsection{Nutritional analysis}

The total nitrogen, phosphorus, potassium, total organic carbon, and trimethylamine were determined at the beginning, in the middle, and at the end of the biotransformation process. Total nitrogen and the 
phosphorus content are determined respectively according to the Kjeldahl method ${ }^{9}$ and the French standard NF V18-106 10 concerning spectrophotometric assay. Potassium is determined by flame emission spectrophotometry (K2+) using flame photometer (Digital Flame Photometer PFP7/C, JENWAY®) ${ }^{10,11}$.

The Total Organic Carbon (TOC) is determined by the Walkley-Black method, based on the oxidation of organic matter with potassium dichromate $\left(\mathrm{K}_{2} \mathrm{Cr}_{2} \mathrm{O}_{7}\right)$ and sulfuric acid mixture, and then titration with ferrous ammonium sulphate ${ }^{12}$.

\subsection{Microbiological analysis and trimethylamine (TMA) dosage}

The microbiological analysis is performed in the beginning and the $15^{\text {th }}$ day of biotransformation, according to NFV08-053, NFV08-057-1 / 2, LV029801 standarts ${ }^{13}$. The presence of Streptococcus (proteolytic effects) and Staphylococcus (lipolytic marker) is determined respectively by a Columbia blood agar and a Mannitol salt agar. The presence of Escherichia coli and Salmonella is determined respectively by a Mac Conkey and SS agar ${ }^{11-14}$.

The dosage of the trimethylamine (TMA) is performed by the distillation according to the EC Regulation $n^{\circ} 2074 / 2005$ for the determination of the
TVB-N (basic amines total volatile). An additional step between the deproteinizing of the sample by perchloric acid and its distillation is integrated by adding the formaldehyde to basic $\mathrm{pH}$ to block the primary and secondary amines, therefore, what remains to be quantified as a form amine is the TMA ${ }^{9}$.

\subsection{Data statistical analysis}

In this study, the optimization of the biotransformation process and duration process depends on the different fractions of organic wastes of the initial mixture. In order to determine the effect of each of the experimental parameters, we adopted the experimental design methodology and response surfaces. These tools are intended to estimate the impact of factors on the nutritional quality of mixtures and the conditions for obtaining a stable and mature product ${ }^{15}$. The ternary surface response diagram and principal component analysis (PCA) are carried out by STATISTICA software®10 (StatSoft, USA).

\subsection{Germination test}

The germination test is done by using of the barley crop and determination of the parameters with the equations bellow ${ }^{16,17}$ :

- The percentages of relative seed germination (RSG)

$$
\text { RSG } \%=\frac{\text { Number of seeds germinated in extract }}{\text { Number of seeds germinated in distilled water(DW) }} * 100
$$

- Relative root growth (RRG)

$$
\text { RRG } \%=\frac{\text { Mean root length in extract }}{\text { Mean root length in distilled water (DW) }} * 100
$$

- Germination index $(\mathrm{GI})$

$\mathrm{GI} \%=\frac{\mathrm{RSG} * \mathrm{RRG}}{100}$

\subsection{Chemical and physicochemical characterization of the soil}

The physicochemical parameters of the soil were measured using previously dried soil, sieved $(<2 \mathrm{~mm})$, and suitably stored. The acidity and the conductivity are determined respectively using a $\mathrm{pH}$-meter and HANNA Instruments EC215. The total nitrogen, phosphorus, and Total Organic Carbon TOC contents are determined by the applicable methods described in the literature 9,10,12. Potassium and sodium ( $\mathrm{Na}$ and $\mathrm{K}$ ) are determined by flame emission spectrophotometry (Digital Flame Photometer PFP7/C, JENWAY®).

\subsection{Toxicity test and fertilization}

The toxicity test of the best mixture on plant germination is done on the Hordeum vulgare species of barley that is provided by the National Institute for Agricultural Research. The tests on barley crops are performed in plastic cases measured $3 \times 4$ cases with a depth of $6 \mathrm{~cm}$; the seeds are deposited at a depth of $3 \mathrm{~cm}$ and covered with soil. Column 1 contained the control soil without amendment, column 2 contained commercial fertilizer (Miracle Gros ${ }^{\circledR}$ ), and column 3 contained bio-transformed products. The application rate of amendments is $0.054 \mathrm{~g}$ per $36 \mathrm{~cm}^{2}$ of soil $(150 \mathrm{~kg} / \mathrm{hectare}$ equivalent, the minimumrecommended by the FAO fertilizer use for cereal crops in Morocco dose ${ }^{18}$ ).

\section{Results and Discussion}

\subsection{Physico-chemical parameters control 3.1.1. Visual aspect of the mixtures}

In the beginning, all compositions formed a heterogeneous thick paste. During the process, M1, M3, and M6 which are devoid of grape marc marked liquefaction compared to the other mixtures. After 15 days of biotransformation, no rotten odor developed in the mixtures; thus, they were characterized by a uniform appearance, a dark color, more specifically in mixtures containing more molasses (Fig.1). Indeed, the dark color of molasses is due to the action of heat 
on proteins in the presence of reducing carbohydrates ${ }^{19}$. These textural observations indicate that the bio-transformed mixtures are ripe at the end of the process.

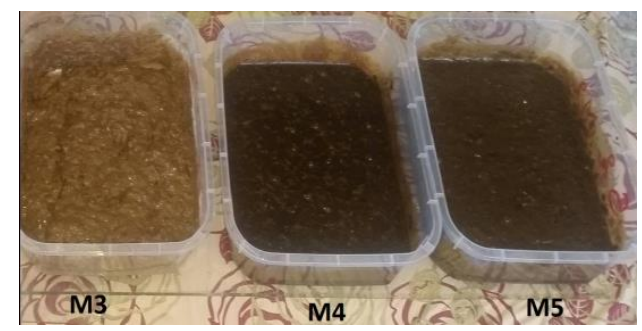

Figure 1. Mixtures 3, 4 and 5 at first day of biotransformation

\subsection{2. $\mathrm{pH}$ and conductivity}

From the result of the $\mathrm{pH}$ monitoring for 15 days shown in Fig.2, it is observed that the $\mathrm{pH}$ of the different mixtures is initially acidic (between 5.52 and 6.60). However, during the biotransformation process, M2, M4, and M5 compositions went from a slightly acidic $\mathrm{pH}(5.82,5.52$, and 6.08 respectively) to a somewhat basic $\mathrm{pH}(8.03,7.89$ and 7.51 respectively). The composition of the initial substrate influences the $\mathrm{pH}$ during biotransformation, hence the slight difference between the treatments. Indeed, the addition of grape marc tends to reduce the $\mathrm{pH}$ of the mixtures, which may be due to the high content of water-soluble carbohydrates in the grape marc, as well as the accumulation of phenolic compounds and tannins thus causing increased resistance to the biological degradation of grape marc ${ }^{20}$. The increase in $\mathrm{pH}$ between the initial state and an advanced state of biotransformation is consistent with data in the literature. Several studies have shown that biotransformed mixtures subjected to right oxygenation conditions have $\mathrm{pH}$ values that quickly reach values close to $8^{21-23}$. The final $\mathrm{pH}$ values of all the tests were ideal (between 6.12 and 8.03) since the yeasts and bacteria involved in the biotransformation have an optimum $\mathrm{pH}$ between 5 and 8.5. These values are consistent with another works ${ }^{24,25}$, which shows that our products are stable, and they will not present any risk for the soil and plants, this result shows reasonable control of biotransformation.

As for conductivity, it shows that the different mixtures start from a value between $3.65 \mathrm{mS} / \mathrm{cm}$ $( \pm 0.11)$ and $7.50 \mathrm{mS} / \mathrm{cm}( \pm 0.62)$ in the upward order $\mathrm{M} 4<\mathrm{M} 5<\mathrm{M} 7<\mathrm{M} 2<\mathrm{M} 3<\mathrm{M} 6<\mathrm{M} 1 \quad$ (Fig. 2). The conductivity increased in all mixtures and finally stabilized between $6.75 \mathrm{mS} / \mathrm{cm}( \pm 0.10)$ and 12.48 $( \pm 0.49) \mathrm{mS} / \mathrm{cm}$. These values are less than $5 \mathrm{mS} / \mathrm{cm}$, which is favourable for the growth of the majority of plants. M2, M4, M5 and M7 composition containing the grape marc had a lower conductivity than the others during the process. Indeed, winery wastes like grape marc also tend to have low electrical conductivity, high organic matter and significant content of phosphorus and potassium ${ }^{26}$. The values obtained corroborate the final less liquid aspects of the mixtures and which can reflect the weak decomposition of the organic matter in the substrates. However, the physical pre-treatment of grape marc in aqueous suspension can damage cells and increase electrical conductivity ${ }^{27}$. The recovered waste contains electrolytes which dissolve during biotransformation, then ionize by increasing the conductivity of the mixtures prepared and decreasing their resistivity. Increased nitrification caused by good ventilation would also have the same effects.
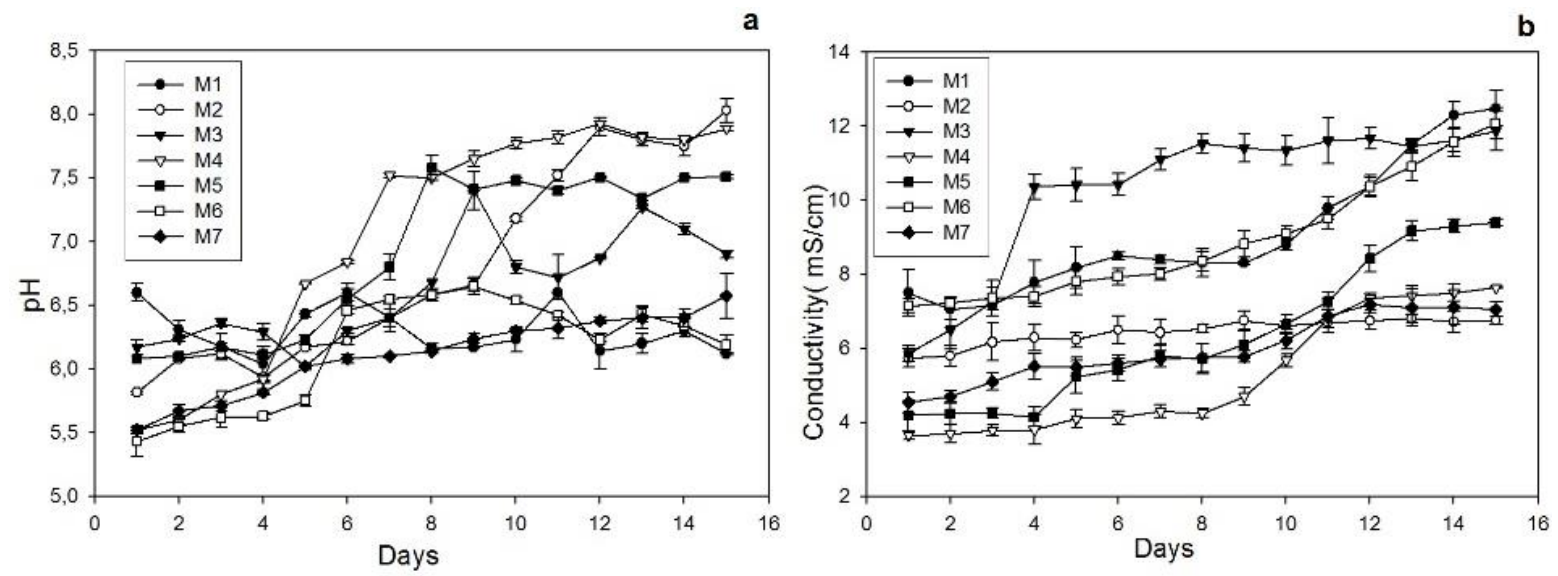

Figure 2. Evolution of $\mathrm{pH}$ (Figure on the left) and of conductivity (Figure on the right), at the beginning, $4^{\text {th }}, 8^{\text {th }}$, $12^{\text {th }}$ and $15^{\text {th }}$ day of biotransformation of the mixtures 


\subsubsection{Temperature and dry matter}

The Fig. 3 describes the evolution over time of the temperature and the dry matter of the different compositions. It is noted that the temperature increases between the beginning and the $3^{\text {rd }}$ day in all of the mixtures (between $18^{\circ} \mathrm{C}$ and $19.9^{\circ} \mathrm{C}$ ). Indeed, this slight rise can be explained by the transformation of sugar and the production of ethanol and organic acids, symbolizing the adaptation of $S$. cerevisiae with the environment studied ${ }^{28}$. Between the $4^{\text {th }}$ and $15^{\text {th }}$ day, the temperatures are more or less stable with nonsignificant variations of the order of $1{ }^{\circ} \mathrm{C}$ in all the mixtures. All mixtures have a temperature that then evolves with the ambient temperature, reflecting proper aeration and in a waymarking the stabilization of our mixtures ${ }^{29}$. The process of biotransformation applied then allows reasonable practical control of temperature.

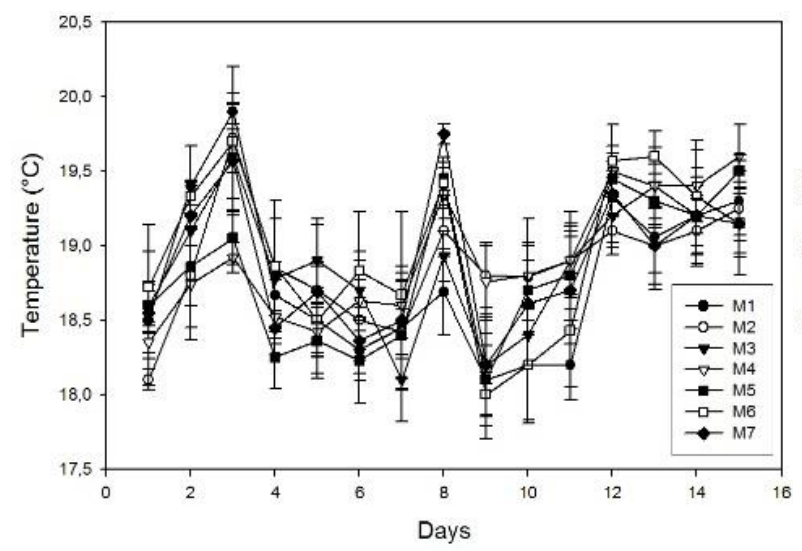

The evolution of the dry matter rate (Fig.3) shows that all the mixtures had initial DM between $35 \%$ and $50 \%$. Indeed, M7 containing 31\% molasses and $18.75 \%$ of grape marc has a high initial rate in MS (50\%) compared to other compositions. During the biotransformation, all the compositions showed a slight increase in MS, and the final levels were between $41.10 \%$ and $56.66 \%$, which means the right level of humidity by their uniform appearance. Also, the increase in the dry matter can lead to the presence of white (a form of resistance of fungi), which translates into a slowing down of microbiological activity ${ }^{30}$. These results provide experimental evidence that Saccharomyces cerivisiae play a favorable role in favoring biotransformation and possibly disadvantaging reactions that tend to release part of the matter by conversion to volatile substances.

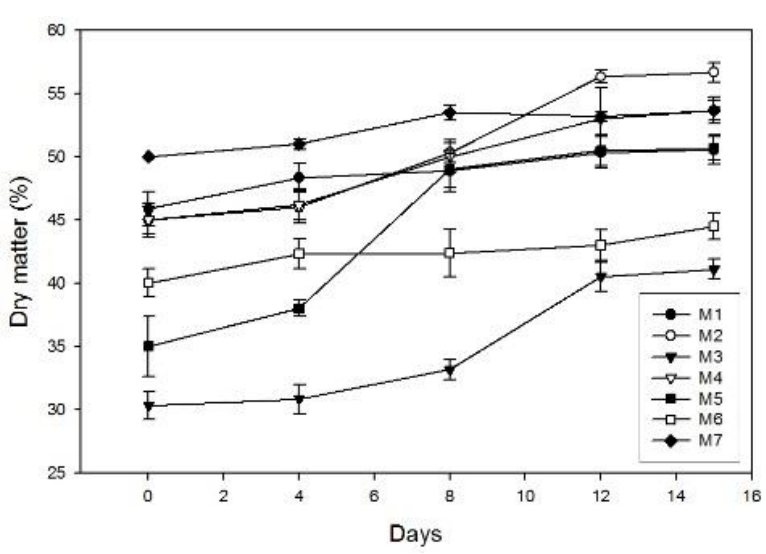

Figure 3. Evolution of the temperature (Figure on the left) and of the dry matter (Figure on the right), at the beginning, $8^{\text {th }}$ and $15^{\text {th }}$ day of biotransformation of the mixtures

\subsection{Evolution of nutritional parameters}

\subsubsection{Mineral phosphorus $(P)$ and total nitrogen} (TN)

The Fig.4 shows the evolution of phosphorus and total nitrogen at the beginning and at the end of the biotransformation process of the mixtures. Between $\mathrm{Ti}$ and $\mathrm{Tf}$, all of the mixtures have increasing phosphorus and nitrogen levels, arriving at different final contents. According to the initial phosphorus level (Pi), it evolves between $(3.54 \pm 0.10$ and $65.55 \pm 0.17 \mathrm{mg} / 100 \mathrm{~g}$ ) for all mixtures in the upward order $\mathrm{M} 3<\mathrm{M} 1<\mathrm{M} 6<\mathrm{M} 5<\mathrm{M} 2<\mathrm{M} 7<\mathrm{M} 4$. However, the M1, M3, and M6 mixtures started with low concentrations of mineral phosphorus $(\mathrm{Pi}=3.70 \pm 0.08 \mathrm{mg} / 100 \mathrm{~g}, 3.54 \pm 0.10 \mathrm{mg} / 100 \mathrm{~g}$, and $3.9 \pm 0.69 \mathrm{mg} / 100 \mathrm{~g}$ ) respectively, because they are devoid of grape marc. The mixture M4 with $50 \%$ of fish waste, $12.5 \%$ of molasses, and $37.50 \%$ of grape marc has a better Pf with $(65.55 \pm 0.17 \mathrm{mg} / 100 \mathrm{~g})$, followed by M2 $(53.48 \pm 0.21 \mathrm{mg} / 100 \mathrm{~g})$ and then M7 $(51.78 \pm 0.36 \mathrm{mg} / 100 \mathrm{~g})$. As for total nitrogen, the best Nf was observed in the M4 (1.50 $\pm 0.05 \%)$ followed by the M5 mixture $(1.34 \pm 0.16 \%)$. Presumably, the final composition of nutrients depends on the sources of substrates that constitute the formula as well as the rate of decomposition that mixes undergo ${ }^{31}$, which explains the variations in phosphorus and nitrogen contents between mixtures, even those with the same starting rate. However, if the grape marc has a low nitrogen and phosphorus interest, one could thus imagine that it can be complemented by other organic by-products rich in nitrogen and phosphorus but more or less soluble and fermentable ${ }^{32}$. The results of this analysis have shown that the addition of grape marc in our formulation can improve the phosphorus and nitrogen levels. 

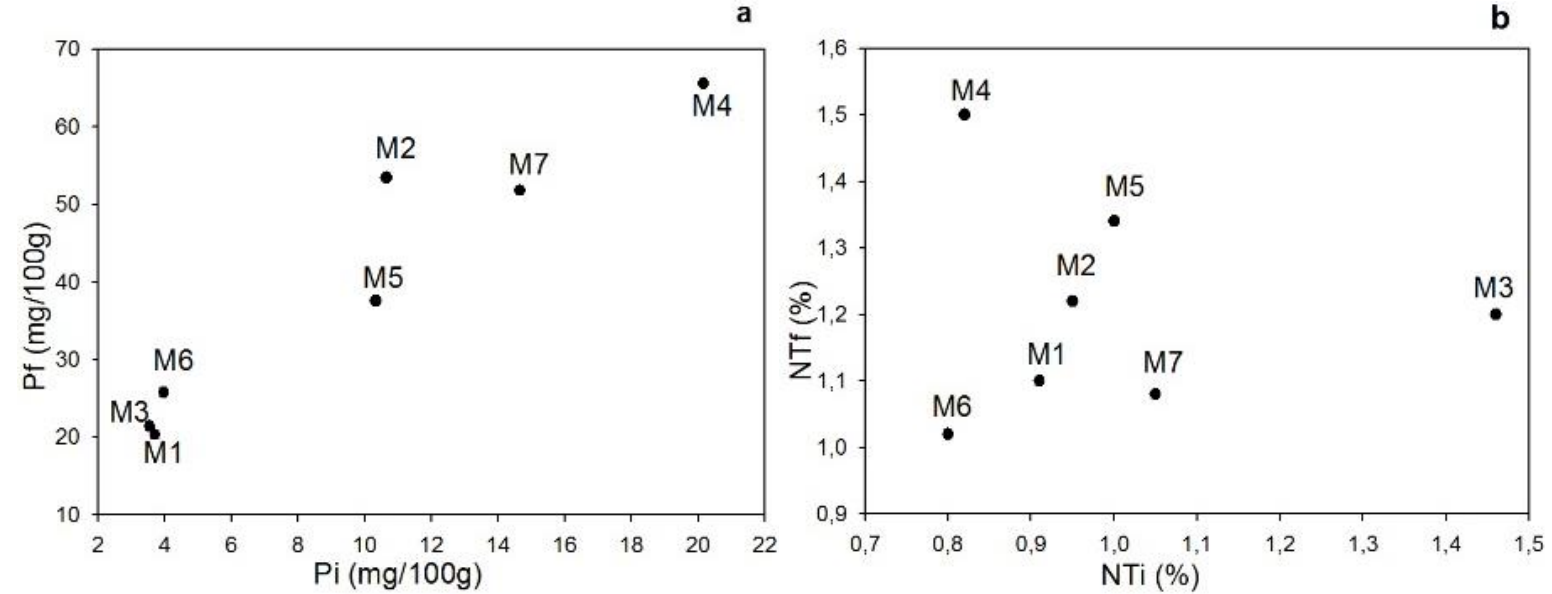

Figure 4. Evolution of phosphorus (Figure on the left) and nitrogen (Figure on the right), at the beginning and the $15^{\text {th }}$ day of biotransformation of the mixtures. Pi and NTi: the initial amount of phosphorus and nitrogen; Pf and NTf: final quantity of phosphorus and nitrogen

\subsubsection{Potassium and Carbon/ Nitrogen ratio}

In cations exchanges, $\mathrm{K}^{+}$potassium ions are released from the decomposition of organic tissues by the microorganisms of the mixture at the rate of mineralization. It is one of the essential macronutrients that the plant needs to develop its biological processes 33,34 . It is present in variable concentrations in the various compositions studied (Fig.5). M3 and M6 mixtures, devoid of grape marc, showed a low Kf, which at start-up (Ki) was already relatively small. M4 and M7 resulted in final concentrations ( $\mathrm{Kf})$ of $1.64 \% \mathrm{DM}$ and $1.55 \% \mathrm{DM})$. Following the final concentration (Kf) we can consider that all the mixtures are rich in potassium, confirming that the grape marc can improve the potassium levels.

It is widely known that the biodegradability of organic waste depends on its carbon/nitrogen ratio $(\mathrm{C} / \mathrm{N})^{8,15}$, hence the need to know the initial and final $\mathrm{C} / \mathrm{N}$ of bio-processed products. This ratio is then calculated as a function of the concentration of TOC and NKT. The $\mathrm{C} / \mathrm{N}$ ratio often evaluates the maturity of bio- transformed mixtures. It is necessary for this ratio of less than 15 at the end ${ }^{8,15}$. Generally, the carbon/ nitrogen ratios decrease during the biotransformation process, this decrease is due to the degradation and mineralization of organic matter, which is confirmed by the intense microbial activity observed during the 15 days of the process.

The level of total organic carbon decreased during this process, as well as the $\mathrm{C} / \mathrm{N}$ ratio, except for $\mathrm{M} 2$ composition, which showed a slight increase; this increase is due to the development of a microbial flora by the contribution of organic matter. The variations in carbon and nitrogen contents of the mixtures affect the $\mathrm{Cf} / \mathrm{Nf}$ ratio, which varies between 9.17 and 19.16 (Fig.5). In addition, all the compositions had an ideal rate at the end. Indeed, a $\mathrm{C} / \mathrm{N}$ ratio of an organic matter is stable if it is between 10 and $25^{35}$. However, the ratio $\mathrm{Cf} / \mathrm{Nf}=9.17$ of $\mathrm{M} 2$ reflects excellent stability, according to other studies ${ }^{36}$. The results indicate a rapid maturity of the mixtures and a favorable evolution, probably by a good $\mathrm{C} / \mathrm{N}$ starting ratio.
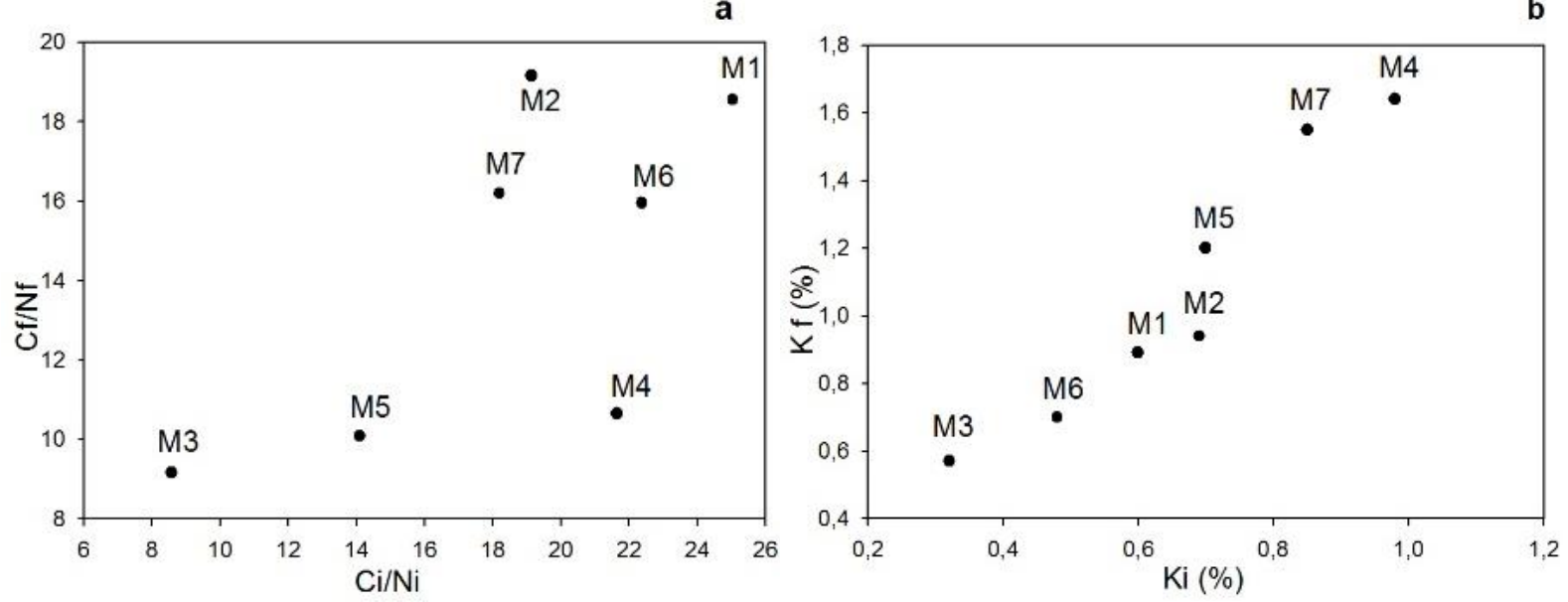

Figure 5. Evolution of $\mathrm{C} / \mathrm{N}$ ratio (Figure on the left) and potassium (Figure on the right) at the beginning and the $15^{\text {th }}$ day. $\mathrm{Ki}$ and $\mathrm{Ci} / \mathrm{Ni}$ : the initial amount of potassium and carbon/ nitrogen ratio; $\mathrm{Kf}$ and $\mathrm{Cf} / \mathrm{Nf}$ : the final amount of potassium and carbon/ nitrogen ratio 


\subsubsection{Trimethylamine (TMA)}

The level trimethylamine was slightly increased in all compositions during the biotransformation process (Fig.6). It was between $0.12 \pm 0.036 \%$ and $0.36 \pm 0.059$
$\%$ for all mixtures. This increase is due to the bacterial reduction of OTMA (trimethylamine oxide) ${ }^{37}$. This result proves the stability and the acceptability of our product $^{8-15}$.

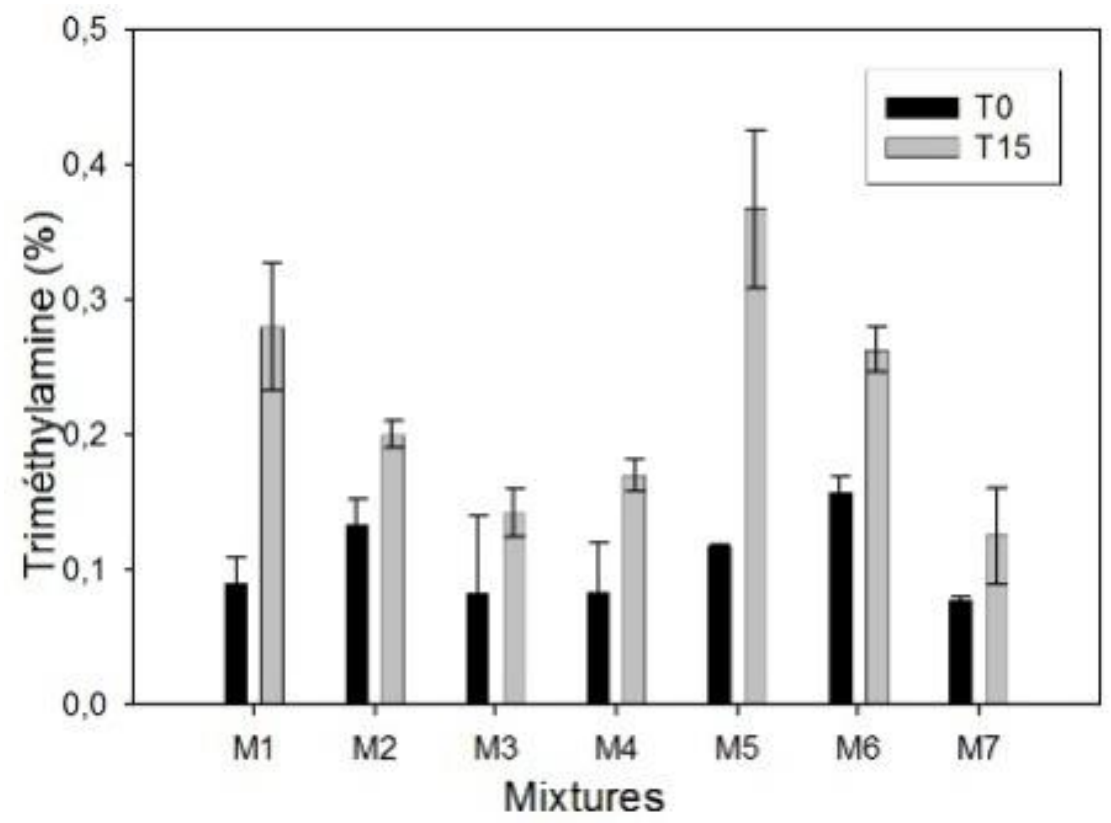

Figure 6. Evolution trimethylamine at the start and on the $15^{\text {th }}$ day of biotransformation of the mixtures

\subsection{Microbiological controls}

Table 2 shows that bacteria (Streptococcus and $E$. coli) appear on the first day (Ti) in all the mixtures studied, thus, at the end of the fermentation process. All the compositions show no presence of E. coli, Staphylococcus, and Streptococcus. The absence of pathogens at the end of biotransformation proves that our products are hygienic and non-toxic. Published works ${ }^{38,39}$ reported that the addition of grape marc in composting processes ensures the destruction of pathogens and other unwanted organisms. Thus, the use $S$. cerevisiae in this study has enabled favorable biotransformation of the by-products studied ${ }^{40,41}$.

Table 2. Microbiological control of mixtures (dilution of 1/10).

\begin{tabular}{|c|c|c|c|c|c|}
\hline & Days & E. coli & Staphylococcus & Streptococcus & Salmonella \\
\hline \multirow{2}{*}{ M1 } & T0 & + & - & ++ & - \\
\hline & $\mathrm{T} 15$ & - & - & - & - \\
\hline \multirow{2}{*}{ M2 } & T0 & + & - & + & - \\
\hline & $\mathrm{T} 15$ & - & - & - & - \\
\hline \multirow[t]{2}{*}{ M3 } & T0 & ++ & - & + & - \\
\hline & $\mathrm{T} 15$ & - & - & - & - \\
\hline \multirow[t]{2}{*}{ M4 } & $\mathrm{T0}$ & + & - & + & - \\
\hline & $\mathrm{T} 15$ & - & - & - & - \\
\hline \multirow[t]{2}{*}{ M5 } & T0 & ++ & - & + & - \\
\hline & $\mathrm{T} 15$ & - & - & - & - \\
\hline \multirow[t]{2}{*}{ M6 } & T0 & ++ & - & ++ & - \\
\hline & $\mathrm{T} 15$ & - & - & - & - \\
\hline \multirow[t]{2}{*}{ M7 } & T0 & + & - & + & - \\
\hline & $\mathrm{T} 15$ & - & - & - & - \\
\hline
\end{tabular}

(++:> 100UFC ; +:>10 CFU - : absence) 


\subsection{Statistical analysis}

\subsubsection{Principal Component Analysis (PCA)}

PCA analysis makes it possible to highlight a particular grouping of individuals, which will be able to be interpreted and explained by variables ${ }^{42}$. The biplot (Fig.7a) and the correlation circle (Fig.7b) allow identifying main components explaining $86.59 \%$ of the total variance. Nitrogen, phosphorus, potassium, and grape marc are correlated with the first component (factor1), which explains $59.67 \%$ of the total variance (Fig.7b). The second component or factor $2(26.92 \%$ of variance) is correlated with molasses and TOC. The biplot (Fig.7a) shows that the variables measured in the biotransformation process may be gathered into three groups related to factor 1 . The first group contains M1 (The richest in grape marc). It is separated from the other mixtures because of its high content nitrogen, phosphorus, and potassium. Thus, the biotransformation process is highly influenced by the mineralization of the organic wastes, and therefore variables such as phosphorus, potassium, total nitrogen, and total organic carbon are relevant in the process. Similarly, the second group made up of M5 and M7 compositions have a different quality from the others. Unlike the third group, which represents the opposite, it is formed by M1, M2, M3, and M6. These compositions are strongly correlated with molasses and total organic carbon, but anticorrelated with the essential elements, as their quality has been judged inadequate.

The results obtained confirm the relevance of mixture number 4 . This is distinguished by its richness in nitrogen, phosphorus, and potassium. According to Fig. $7 b$, we can see that the addition of marc waste from the raisins contributes to improving the capacity of the product by the chemical elements used in plant cultures $(\mathrm{N}, \mathrm{P}$, and $\mathrm{K})$.
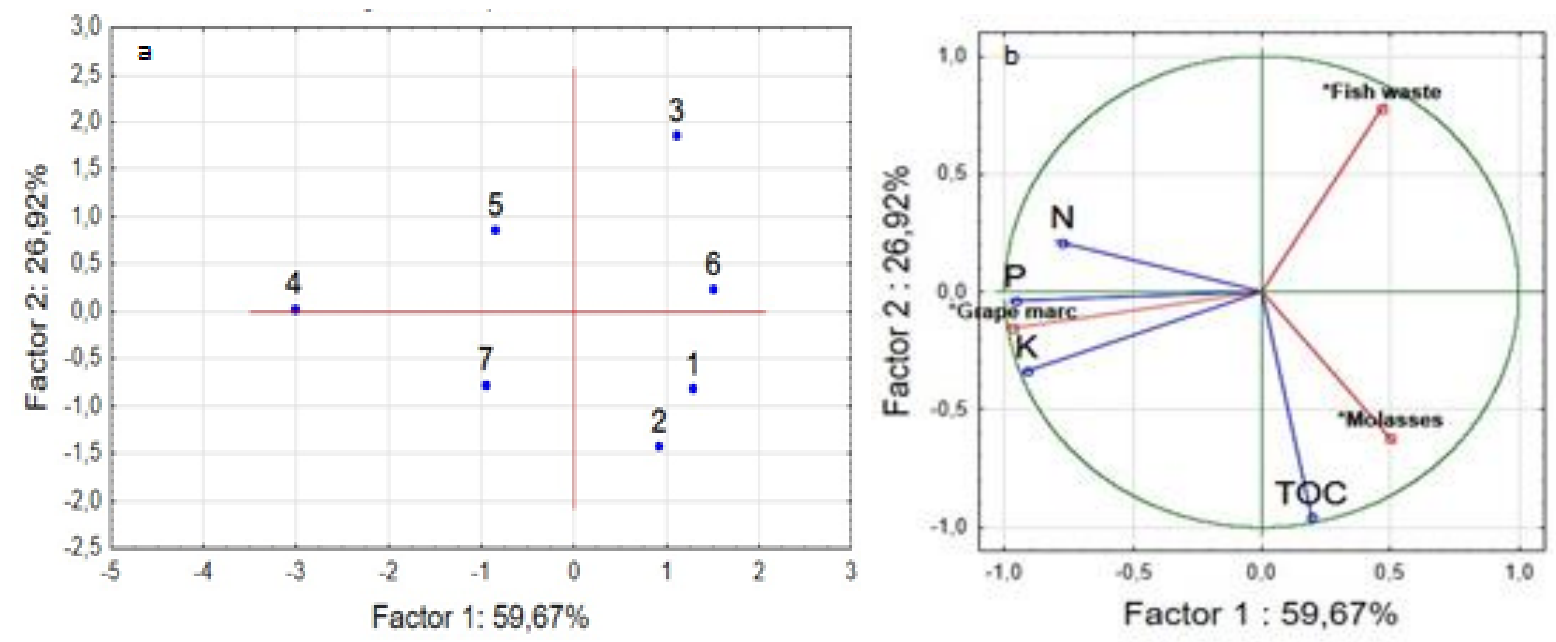

Figure 7. (a) The Biplot consisting projection on PC1 (59.67\%) and PC2 (26.92\%), (b) Correlation circle between principal components and with variables

\subsubsection{Response surface model estimates}

Ternary response surface diagrams with changes in phosphorus, nitrogen, potassium, and total organic carbon are shown in Fig.8. The red-shaded region in the ternary diagram of this figure indicates possible mix formulations that would meet the desired nutritional quality of the bio-fertilizer. The zone around the M4 mixture is the most favorable for all parameters. The properties of bio-transformed mixtures were then in good agreement with the predicted values of the response surface models of desired nutritional elements in bio-fertilizer.

\subsection{Test results on the barley crop}

3.5.1. Characterization of commercial fertilizer and experimental soil

Table 3. presents the results of the physicochemical properties of the experimental soil and the mineral content of the commercial fertilizer. The results reveal that the experimental soil can be used to test the biotransformed product (M4) in the barley crop; it is judged as a good quality soil ${ }^{43}$.

Table 3. Some physicochemical properties of commercial fertilizer and experimental soil.

\begin{tabular}{|c|c|c|c|c|c|c|c|}
\hline Parameter & $\mathbf{p H}$ & $\mathbf{T N}(\boldsymbol{\%})$ & $\mathbf{P}(\boldsymbol{\%})$ & $\mathbf{K}(\boldsymbol{\%})$ & $\mathbf{N a}(\boldsymbol{\%})$ & TOC (\%) & $\begin{array}{c}\text { Cond- } \\
(\mathbf{m S} / \mathbf{c m})\end{array}$ \\
\hline Control soil & 6.54 & 0.74 & 0.14 & 0.61 & 0.2 & 5.56 & 1.61 \\
\hline Commercial Fertilizer & 6.70 & 12.00 & 6.00 & 8.00 & - & - & - \\
\hline
\end{tabular}



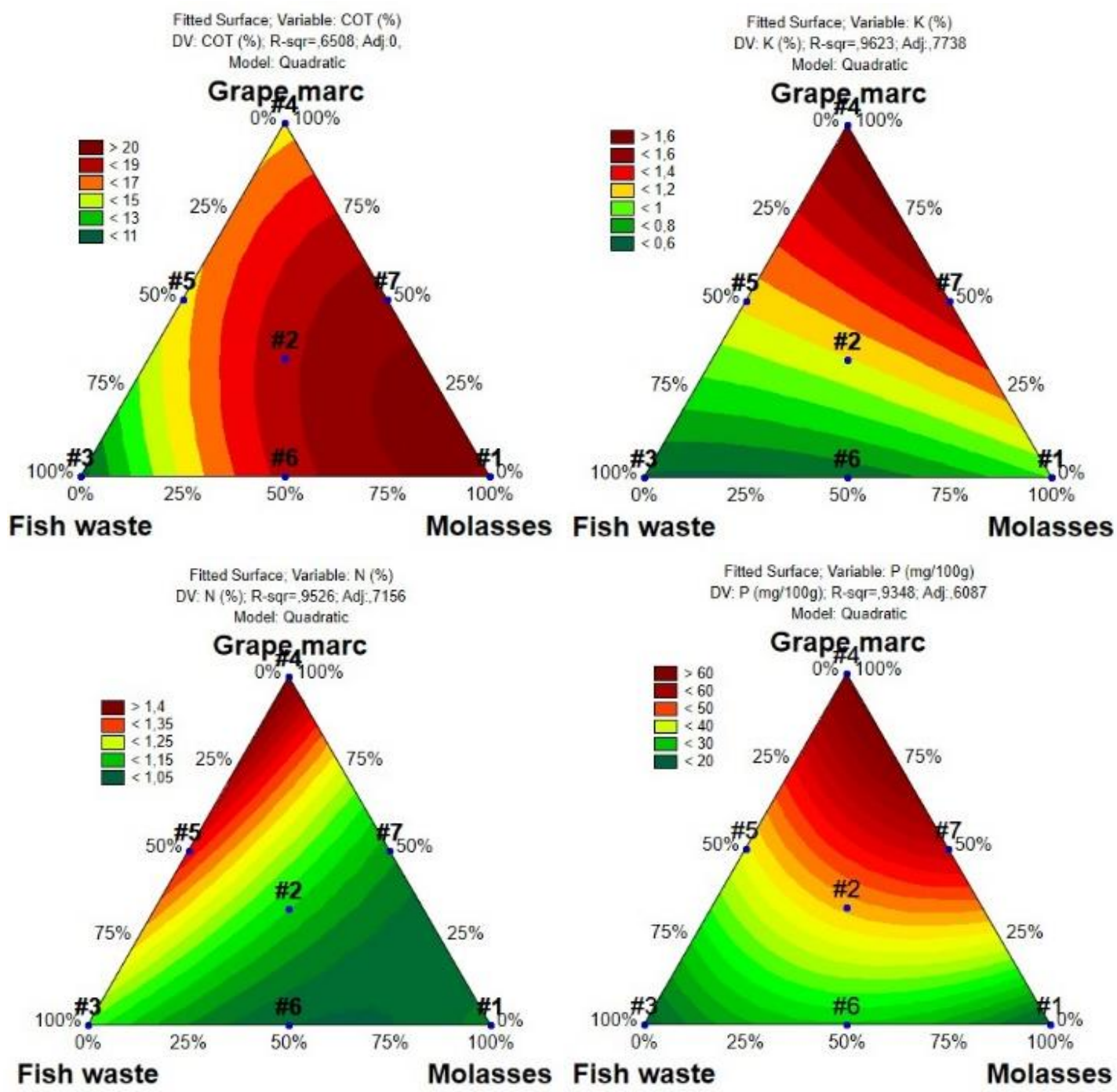

Fish waste

Molasses Fish waste

Molasses

Figure 8. Ternary response surface diagrams with changes in phosphorus, nitrogen, potassium and total organic carbon concentration calculated from the fitted model equations (Quadratic model R-sqr>70\%)

\subsubsection{Germination test}

The bio-transformed mixture contains elements potentially necessary for plant growth. We thought of using it as a bio-fertilizer; however, its application depends on the absence of any toxicity. An assay determined the phytotoxicity of the bio-transformed product and of the commercial fertilizer on the $72 \mathrm{~h}$ at the same dilution. The phytotoxicity test on barley shows that M4 composition has no inhibitory effect on the germination, and the value of the germination index (GI) reached about $53 \%$ for the commercial fertilizer and $73 \%$ for the biological product. These values imply the feasible development of a biofertilizer (M4) based on bio-transformed organic wastes (fish wastes, molasses, and grape marc).

\section{Barley culture test results}

The study of the toxicity of the bio-fertilizer on germination in the underground culture of the variety studied was achieved by determining the average length of the primary roots and the length of the stems. The results of the barley culture tests for 21 days (carried out four times) are illustrated in Table 4. The results obtained show that the biological formula (M4), which had the best nutritional effect, allows the optimal growth of barley crop. These results could be explained by the good $\mathrm{C} / \mathrm{N}$ ratio allowing better mineralization, so this formula releases the nutrients it contains much faster to make them available to plants ${ }^{47}$. The assimilable forms by plants are provided by our bio-fertilizer developed by biotransformation under the action of $S$. cerevisiae.

Table 4. Fertilization test on barley culture (21 days of culture).

\begin{tabular}{|l|c|c|c|}
\hline & Control soil & $\begin{array}{c}\text { Soil + commercial } \\
\text { fertilizer }\end{array}$ & $\begin{array}{c}\text { Soil+ bio-transformed } \\
\text { product (M4) }\end{array}$ \\
\hline Average stem length $(\mathbf{c m})$ & $15.65 \pm 0.91$ & $20.08 \pm 1.12$ & $19.39 \pm 1.30$ \\
\hline Average root length $\mathbf{( c m )}$ & $18.62 \pm 0.93$ & $17.71 \pm 1.32$ & $20.74 \pm 1.07$ \\
\hline
\end{tabular}




\section{Conclusion}

The valuation of wastes and by-product of agri-food industries by the biotransformation using mixture designs and triangular surfaces of iso-responses strategy allows generating exciting products for agricultural fertilization.

The biotransformation of a mixture consisting of approximately $50 \%$ of fish waste, $12.5 \%$ molasses, and $37.50 \%$ grape marc is an optimal formulation to generate a product rich in the nutrients essential for optimal growth plants: nitrogen, phosphorus, and potassium. On the other hand, most unfavorable mixtures are attached to formulations 1,3 , and 6 . These formulas do not integrate the grape marc in their composition. This confirms the favorable contribution and the beneficial contribution of this component, namely to balance the biotransformation mixtures.

\section{References}

1- A. Schieber, F.C. Stintzing, R. Carle, Byproducts of plant food processing as a source of functional compounds-recent developments, Trends in Food Science \& Technology, 2001, 12, 401-413.

2- M. Mäkelä, C. W. Kwong, M. Broström, K. Yoshikawa, Hydrothermal treatment of grape marc for solid fuel applications, Energy Conversion and Management, 2017, 145, 371-377.

3- G. Laufenberg, B. Kunz, M. Nystroem, Transformation of vegetable waste into value added products: (A) the upgrading concept; (B) practical implementations, BioresourceTechnology,2003, 87, 167-198.

4- L. Zhang, X. Sun, improving green waste composting by addition of sugarcane bagasse and exhausted grape marc, Bioresource Technology, 2016, 218, 335-343.

5- J. Yu, M. Ahmedna, Functional components of grape pomace: their composition, biological properties and potential applications, International Journal of Food Science \& Technology, 2013, 48, 221-237.

6- K. Dwyer, F. Hosseinian, M. Rod, The Market Potential of Grape Waste Alternatives, Journal of Food Research, 2014, 3, p91.

7- R. Bayard, R. Gourdon and L. Thiery, Aide à la définition des déchets dits biodégradables, fermentescibles, méthanisables, compostables, Rapport final, Association RECORD, Contrat n 00-0118 A 1, 2001, 1, p2001.

8- T. Taiek, N. Boutaleb, B. Bahlaouan, A. El Jaâfari, V. Le Tilly, O. Sire, S. El Antri, Biotransformation de déchets halieutiques au Maroc-Essais de production d'un fertilisant biologique, Techniques Sciences Méthodes, 2014, 11,158-171.

9- D. Ait Saada, O. Ait Chabane, A. Bekada, K. Bouderoua, R. Keddam, L. Boukhalfa,
J. Mourout, G. Selselet-Attou, Valorization. Essay of Arthrospiraplatensis in Alimentation of Broilers, Global Veterinaria, 2016, 16, 71-85.

10-S.B. Ayssiwede, A. Dieng, C. Chrysostome, W. Ossebi, J. L. Hornick, A. Missohou, Digestibility and metabolic utilization and nutritional value of Leucaena

leucocephala (Lam.) leaves meal incorporated in the diets of indigenous Senegal chickens,

International Journal of Poultry Science, 2010, 9, 767-776.

11-M. Balakrishnan, R. S. Simmonds, M. Kilian, J. R. Tagg, Different bacteriocin activities of Streptococcus mutans reflect distinct phylogenetic lineages, Journal of Medical Microbiology, 2002, 51, 941-948.

12-A. Brian, Methods for the determination of total organic carbon (TOC) in soils and sediments, Ecological Risk Assessment Support Center, 2002, 1-23.

13-G.C. Sean, A. Prasad, W.L. Smith, E. Mordechai, M. Adelson, S.E. Gygax, Detection of Epidemic USA300 Community-Associated MethicillinResistant Staphylococcus Aureus Strains by Use of a Single Allele-Specific PCR Assay Targeting a Novel Polymorphism of Staphylococcus aureus pbp3, Journal of Clinical Microbiolog, 2013, 51, 2541-2550.

14-R. W. Smyth, G. Kahlmeter, Mannitol salt agarcefoxitin combination as a screening medium for methicillin-resistant Staphylococcus aureus, Journal of Clinical Microbiology, 2005, 43, 3797-3799.

15-D. Lakhal, N. Boutaleb, B. Bahlaouan, N. Abouakil, M. Mekouar, A. Fathi, A. Lazar, S. El Antri, Mixture experimental design in the development of a bio fertilizer from fish waste, molasses and scum, International Journal of Engineering Research and Technology, 2017,6, 588-594

16-J. K. Kim, I. S. Kong, H. H. Lee, Identification and characterization of microorganisms from earthworm viscera for the conversion of fish wastes into liquid fertilizer, Bioresource Technology, 2010, 101, 5131-5136.

17-B. El Fassi, M. Idaomar, Elimination of phytotoxicity during cocomposting of animal casing waste and sawdust, International Journal of Research, 2014, 1, 2311-2484.

18-FAO, Food and Agriculture Organization of the United Nations, Utilisation des engrais par culture au Maroc, Première édition, Rome, 2006.

19-R. Christon, J. Le Dividich, Utilisation de la mélasse de canne a sucre dans l'alimentation du porc : essai d'interprétation des acquisitions récentes, In Annales de zootechnie, 1978, 27, 267-288.

20-M.A. Bustamante, C. Paredes, F.C. MarhuendaEgea, A. Perez-Espinosa, M. P. Bernal, R. Moral, Co-composting of distillery wastes with animal manures: Carbon and nitrogen transformations in 
the evaluation of compost stability,

Chemosphere, 2008, 72, 551-557.

21-F. C. Michel, C. A. Reddy, Effect of oxygenation level on yard trimmings composting rate, odor production, and compost quality in bench-scale reactors, Compost Science \& Utilization, 1998, 6, 6-14.

22-Y. Eklind, H. Kirchmann, Composting and storage of organic household waste with different litter amendments. II: nitrogen turnover and losses, Bioressource Technology, 2000, 74, 125-133.

23-M. A. Sanchez-Monedero, A. Roig, C. Paredes, M. P. Bernal, Nitrogen transformation during organic waste composting by the rugers system and its effects on $\mathrm{pH}, \mathrm{EC}$, and maturity of the composting mixtures, Bioressource Technology, 2001,78, 301-308.

24-M. De Bertoldi, G. Vallini, A. Pera, The biology of composting: a review, Waste Management \& Research, 1983, 1, 157-176.

25-F. C. Miller, F.B. Metting Jr, composting as a process based on the control of ecologically selective factors, Soil microbial ecology: Applications in Agricultural and Environmental Management, 1992, 515-544.

26-M. A. Bustamante, D. Said-Pullicino, E. Agullo, J. Andreu, C. Paredes, R. Moral, Application of winery and distillery waste composts to a Jumilla (SE Spain) vineyard: effects on the characteristics of a calcareous sandy-loam soil, Agriculture Ecosystems Environment, 2011, 140, 80-87.

27-N. Lebovka, M. Bazhal and E. Vorobiev, Estimation of characteristic damage time of food materials in pulsed-electric fields, Journal of Food Engineering, 2002, 54, 337-346.

28-A. Y. Tamine and R. K. Robinson, Yogur: ciencia y Tecnologia, Acridia SA, Zaragoza, Spain, 1990, 55-87.

29- W. Chad Higgings, L.P. Walker, Validation of a new model for aerobic organic solids decomposition: simulation with substrate specific kinetics, Process Biochemistry, 2001, 36, 875- 884.

30-W. Holzapfel, Use of starter cultures in fermentation on a household scale, Food Control, 1997, 8, 241-258.

31-J. H. Crawford, Composting of agricultural wastes--a review, Process Biochemistry, 1983, 18, 14-14.

32-C. Dermarquilly, J. Andrieu, D. Sauvant, J.P. Dulphy, Composition et valeur nutritive des aliments, In Alimentation des ruminants, INRA publ, Versailles, 1978, 469-518.

33-B. B. Basak, D.R. Biswas, Influence of potassium solubilizing microorganism (Bacillus mucilaginosus) and waste mica on potassium uptake dynamics by sudan grass (Sorghum vulgare Pers.) grown under two Alfisols, Plant and Soil, 2009, 317, 235-255.

34-W. Liu, X. Xu, X. Wu, Q. Yang, Y. Lou, P. Christie, Decomposition of silicate minerals by Bacillus mucilaginosus in liquid culture, Environmental Geochemistry and Health, 2006, 28, 133-140.

35-E. H. El Herradi, B. Soudi, F. Naman, Valorisation des déchets ménagers par extraction des substances humiques, Journal of Materials and Environmental Sciences, 2014, 5, 1382-1389.

36-M. Bouché, Lombriciens de France, Ecologie et Systématique, Ann. Zool. Ecol. Anim., INRA, 1972, numéro special 72.2, 1-671.

37-M. K. Nielsen, B M. Jorgensen, Quantitative relationship between trimethylamine oxide aldolaseactivity and formaldehyde accumulation in white muscle from gadiform fish during frozen storage, Journal of Agricultural and Food Chemistry, 2004, 52, 3814-3822.

38-M. A. Bustamante, A.P. Restrepo, J.A. Alburquerque, M.D. Perez-Murcia, C. Paredes, R. Moral, M.P. Bernal, Recycling of anaerobic digestates by composting: effect of the bulking agent used, Journal of Cleaner Production, 2013, 47, 61-69.

39-R. Paradelo, A. B. Moldes, M.T. Barral, Evolution of organic matter during the mesophilic composting of lignocellulosic winery wastes, Journal of environmental management, 2013, 116, 18-26.

40-D. Lakhal, B. Bahlaouan, N. Boutaleb, A. Fathi, S. Lazar, S. El Antri, Biotransformation des déchets de l'industrie agroalimentaire et génération d'un fertilisant pour les cultures agricoles, Techniques Sciences Méthodes, 2018, 9, 43-51.

41-D. Lakhal, B. Bahlaouan, N. Boutaleb, A. Fathi, T. Aiek, N. Abouakil, S. Lazar, S. El Antri, Biotransformation of Ternary Mixture of Organic Industrial Waste into Poultry Feed, Journal of Agricultural Science and Technology A, 2018, 3, 171-181.

42-B. K. Lavine, C.E. Davidson, J. Ritter, D.J. Westover, T.Hancewicz, Varimax extended rotation applied to multivariate spectroscopic image analysis,Microchemical Journal, 2004, 76, 173-180.

43-H. Vedie, Fertilité chimique du sol : Savoir interpréter les analyses pour gérer les apports d'éléments majeurs en maraichage biologique, Rencontres techniques, 2008, 2-3.

44-M. Alexander, Introduction to Soil Microbiology, John Wiley Eds., Library of Congress Catalog Card number: 61-11512, 1994. 